Article

\title{
An Application of Time-Dependent Holding Costs and System Reliability in a Multi-Item Sustainable Economic Energy Efficient Reliable Manufacturing System
}

\author{
Mitali Sarkar ${ }^{1}\left(\mathbb{D}\right.$, Sungjun Kim $^{2}$, Jihed Jemai ${ }^{3}{ }^{\mathbb{C}}$, Baishakhi Ganguly ${ }^{4}$ and Biswajit Sarkar ${ }^{2, *} \mathbb{C}$ \\ 1 Department of Industrial Engineering, Yonsei University, 50 Yonsei-ro, Sinchon-dong, Seodaemun-gu, \\ Seoul 03722, Korea \\ 2 Department of Industrial \& Management Engineering, Hanyang University, Ansan, Gyeonggi-do 155 88, Korea \\ 3 Department of Industrial Engineering, Hanyang University, Seoul 04763, Korea \\ 4 Department of Mathematics \& Statistics, Banasthali Vidyapith, Rajasthan 304 022, India \\ * Correspondence: bsbiswajitsarkar@gmail.com; Tel.: +82-10-7498-1981
}

Received: 2 June 2019; Accepted: 20 July 2019; Published: 25 July 2019

\begin{abstract}
Sustainable efficient energy is the key factor of any sustainable manufacturing system. This study addresses a multi-item sustainable economic energy efficient reliable manufacturing quantity (MSEEERMQ) model. The manufacturing system produces defective products during long-runs, where those products may be reworked under the optimum effect of energy and carbon footprint with some costs. As all products are not sold immediately, the holding cost increases based on time. The management decides the system design variable to reduce energy consumption cost and increase system reliability under some time-dependent holding costs, and the optimum energy such that the maximum profit of the production model is obtained with a system reliability as a decision variable. The inflation and time-value of money are considered to calculate the cost of the production model under efficient energy. Using control theory, an Euler-Lagrange method is employed to obtain the sustainable critical path, which gives the optimal solution of the model. There are two lemmas to prove the global optimal solution of the model through the control theory. There is an illustrative example to test the model. Under different conditions there are other two examples with graphical representation and sensitivity analysis. Numerical studies reveal that maximum profit is obtained at the optimal value of the decision variable.
\end{abstract}

Keywords: energy; sustainable manufacturing system; multi-item production; variable holding cost; inflation; control theory

\section{Introduction}

In reality, optimization through control theory is a critical challenge for any researcher for any production model under optimum energy. An economic energy efficient reliable manufacturing quantity (EEERMQ) model is one of the challenging research areas (Cárdenas-Barrón et al. [1]). To make a system reliable, the management system of any production industry sector under efficient energy has to follow several steps towards the reliability of machinery systems and products. The sustainable energy efficient economic reliable manufacturing quantity model (SEEERMQ) is the extended version of the EEERMQ with the concept that the type of production quantity is always sustainable, i.e., for any amount of order quantity from the buyer or retailer, the EEERMQ is almost similar in every production system. Thus, to reach the optimum EEERMQ, the production system must be stable. It means that the management needs $100 \%$ reliable products, which is achievable when the machinery system under the optimum energy consumption works within their capacity. All labors work properly, support of redundancy machines are available, no defective items are produced or if produced, all defective 
items are discarded from the system. To make reliable products, the industry has to choose one option in between two possible options such as (i) invest more funds to make the system energy efficient reliable or (ii) without investment, reduce the system failure rate under optimum energy consumption. Sana [2] is the pioneer researcher in this field of study. He introduced the above second condition, that without investment the failure rate can be reduced. He used the concept of development cost of Mettas [3] but both of them did not think about efficient energy. Cao and Schiniederjans [4] examined the cost of inventory and production cost in just-in-time production systems but they considered constant production cost without any energy and carbon footprint efficiency whereas the time-dependent variable production cost is more relevant for any sustainable manufacturing system. Wang [5] developed a free-repair warranty policy for defective products which come with an economic manufacturing system. Giri and Dohi [6] generated the basic economic manufacturing model with a random breakdown and repair, where they considered that time for repair corrective maintenance, and preventive maintenance was a random variable. They considered a variable production rate, but none of them considered any concept of energy consumption or any energy reduction policy. Sarkar et al. [7] extended the model of Giri and Dohi [6] with variable safety stock but with constant production rate and perfect production system without any energy and carbon footprint effect. Sarkar et al. [8] extended their own model with imperfect production with constant production rate, but they did not consider any concept of sustainable energy issue. Sarkar et al. [9] extended Sana's [2] model with a stock-dependent demand pattern. They proved that a stock-dependent demand pattern is the best when imperfect production is considered with constant production rate but they did not think about the sustainability issue. Chiu et al. [10] obtained the best replenishment policy of the economic manufacturing quantity model where defective products and multiple shipments are considered. The production rate was considered in this case. They indicated that just-in-time manufacturing systems can converge over basic economic manufacturing models without any sustainable choice. Sarkar et al. [11] extended the basic economic manufacturing quantity model with a time-dependent production rate, where inflation and time-value of money is considered with constant holding cost. They found that holding cost is very sensitive to the EMQ model. That is the reason for this proposed model to consider time-dependent holding cost. By introducing an advertising cost, a selling-price-dependent demand and a variable holding cost, Sarkar [12] developed an economic manufacturing quantity (EMQ) model with failure rate as a decision variable, but did not think about efficient energy consumption. Sarkar et al. [13] extended the basic EMQ model with time-dependent holding cost, variable demand and variable material cost, which depends on failure rate i.e., less material cost indicates low standard material and high failure. Sarkar and Saren [14] extended Wang's [5] model with inspection errors and warranty costs, but they considered a constant production rate. Omair et al. [15] explained a sustainable production system which can give profits. Jaber et al. [16] first proved that the basic production model is more effective than a just-in-time manufacturing system where entropy cost, specifically energy, effects and worker's stress are added. They proved that just-in-time manufacturing systems can produce more waste than the basic manufacturing model if the shipment is more frequent. They considered this for both EMQ and JIT models, which where effective to reduce holding inventory and others. Ahmed and Sarkar [17] proved that a sustainable production system can be obtained if the production system can be made under triple bottom line approach (like economic, environmental, and social) but they did not consider any effect of energy. Tiwari et al. [18] discussed the sustainable inventory in a basic inventory model, but no one till now has considered the production of multi-products with time-dependent production rate under sustainable manufacturing systems. This model fulfils the gap of multi-product in a SERMQ model where the holding costs are time-dependent and the model is solved using control theory. Recently, Sarkar and Sarkar [19] developed a smart production system with the effect of energy, but the main issue remains the same; using a traditional production system, how can an industry can make a sustainable energy efficient production system? There are several studies (Kluczek [20] and Harris et al. [21], Dehning et al. [22]) considering how smart production solved the issues of 
efficient energy and all other issues like waste management (Khalil et al. [23], Nižetić et al. [24], Biel and Glock [25]), but not all industries can adopt the smart production system. Therefore, how those industries can solve their issues with efficient energy effects under the traditional manufacturing system is addrssed in this study. Table 1 shows the comparison among different studies in this field of study.

Table 1. Comparison between the contributions of different authors.

\begin{tabular}{|c|c|c|c|c|c|c|}
\hline Author (s) & $\begin{array}{l}\text { Type of } \\
\text { Model }\end{array}$ & $\begin{array}{l}\text { Product } \\
\text { Type }\end{array}$ & $\begin{array}{c}\text { Energy Efficient (EE) } \\
\text { and Reliable (R) }\end{array}$ & $\begin{array}{l}\text { Product } \\
\text { Category }\end{array}$ & $\begin{array}{c}\text { Unit Production } \\
\text { Cost }\end{array}$ & Energy \\
\hline $\begin{array}{c}\text { Mettas (2000) } \\
\text { Cao and }\end{array}$ & EPQ & P\&I & $\mathrm{R}$ & Single & Variable & NA \\
\hline Schiniederjans (2004) & EPQ & $\mathrm{P}$ & NA & Single & Constant & NA \\
\hline Wang (2004) & EPQ & P\&I & NA & Single & Constant & NA \\
\hline Giri and Dohi (2005) & EMQ & $\mathrm{P}$ & $\mathrm{R}$ & Single & Constant & NA \\
\hline Sana (2010) & EMQ & P\&I & $\mathrm{R}$ & Single & Variable & NA \\
\hline Sarkar et al. (2010) & EMQ & $\mathrm{P}$ & $\mathrm{R}$ & Single & Variable & NA \\
\hline Chiu et al. (2011) & EMQ & P\&I & NA & Single & Constant & NA \\
\hline $\begin{array}{l}\text { Sarkar (2012) } \\
\text { Cárdenas- }\end{array}$ & EMQ & P\&I & $\mathrm{R}$ & Single & Variable & NA \\
\hline $\begin{array}{l}\text { Barrón et al. (2013) } \\
\text { Sarkar and }\end{array}$ & & & & & & \\
\hline Saren (2016) & EPQ & P\&I & NA & Single & Constant & NA \\
\hline Jaber et al. (2017) & SEPQ & $\mathrm{P}$ & NA & Single & Constant & Energy \\
\hline $\begin{array}{c}\text { Omair et al. (2017) } \\
\text { Ahmed and }\end{array}$ & EPQ & $\mathrm{P}$ & NA & Single & Constant & NA \\
\hline Sarkar (2018) & SEPQ & $\mathrm{P}$ & NA & Single & Constant & NA \\
\hline Tiwari et al. (2018) & EMQ & $\mathrm{P}$ & NA & Single & Constant & NA \\
\hline This Model & MSEEEMQ & P\&I & $\mathrm{EE} \& \mathrm{R}$ & Multiple & Variable & Energy \\
\hline
\end{tabular}

$\mathrm{P}, \mathrm{I}$, and NA indicate perfect products, imperfect products, and not applicable, respectively.

From Table 1, it can be concluded that there is a big research gap in multi-item sustainable economic energy efficient reliable manufacturing quantity models in the direction of the effect of energy. There are several studies, but no one has considered the effect of energy. Many existing models considered a constant unit production rate, but in reality it generally depends on the rate of production. In this direction, almost all models developed for single products; this model includes some issues that can contribute to obtain sustainable processes. This proposed research fulfills the research gap.

\section{Problem Definition, Notation, and Assumptions}

This section consists of problem definition, notation, and assumptions of the model.

\subsection{Problem Definition}

The aim of the model is to obtain the optimal design variable for a multi-item economic energy efficient reliable manufacturing quantity model with maximum profit. The production system is being made sustainable with the help of system reliability and efficient use of energy. A basic manufacturing system is considered for this purpose. The effect of energy is considered within each sector of the production system. As for long-time holding, the holding cost is never constant. Thus, a time-dependent holding cost under the effect of inflation and time-value of money is considered to calculate the profit. The defective products are produced with a random rate. Hence, excess energy consumptions are there for reworking those defective products into perfect products. To make a sustainable energy efficient production system, the carbon footprint is taken into consideration. The demand pattern should be time-dependent and selling-price-dependent which can give more profit than the unrealistic constant demand. The profit is maximized for the sustainable manufacturing system with the help of the Euler-Lagrange theory under the use of optimal energy. 


\subsection{Notation}

The notation of this model is given in Table 2.

Table 2. Notation for index, variables and parameters.

\begin{tabular}{|c|c|}
\hline \multicolumn{2}{|l|}{ Index } \\
\hline$i$ & number of products $i=1,2, \ldots, n$ \\
\hline \multicolumn{2}{|c|}{ Decision variables } \\
\hline$\eta$ & failure rate of the manufacturing system of product $i$ \\
\hline \multicolumn{2}{|c|}{ Parameters } \\
\hline$A$ & development cost without the energy and carbon footprint cost (\$/unit) \\
\hline$A^{\prime}$ & energy and carbon footprint cost for developing product (\$/unit) \\
\hline$B$ & cost related with system technology and reliability \\
\hline$C_{i}$ & inspection cost without energy consumption cost of product $i,(\$ /$ unit) \\
\hline$C_{i}^{\prime}$ & energy and carbon footprint cost for inspection of product $i,(\$ /$ unit) \\
\hline$C_{d_{i}}$ & reworking cost of product $i$ without the energy and carbon footprint cost (\$/unit) \\
\hline$C_{d_{i}}^{\prime}$ & energy and carbon footprint cost for reworking of product $i$ ( $\$ /$ unit) \\
\hline$C_{p_{i}}^{u_{i}}$ & manufacturing cost without energy and carbon footprint cost of product $i$ ( $\$ /$ unit) \\
\hline$C_{p_{i}}^{\prime \prime}$ & energy and carbon footprint cost for manufacturing product $i$ (\$/unit) \\
\hline$C_{0_{i}}$ & material cost of product $i,(\$ /$ unit) \\
\hline$C_{0_{i}}^{\prime \prime}$ & material cost for energy of product $i$, (\$/unit) \\
\hline$k^{v_{i}}$ & scaling parameter of design variable \\
\hline$p_{i}$ & selling-price product $i$ (\$/unit) \\
\hline$p_{\max }$ & maximum value of selling price ( $\$ /$ unit) \\
\hline$p_{\min }$ & minimum value of selling price ( $\$ /$ unit) \\
\hline$Q_{i}$ & lot size of product $i$, (unit) \\
\hline$\widetilde{T}$ & length of production cycle (year) \\
\hline$\tau$ & inflation rate and time-value of money \\
\hline$\alpha$ & tool/die cost without energy and carbon footprint cost (\$/unit) \\
\hline$\eta_{\max }$ & maximum value of failure rate \\
\hline$\eta_{\min }$ & minimum value of failure rate \\
\hline \multicolumn{2}{|c|}{ Expressions } \\
\hline$C_{h_{i}}$ & $\begin{array}{l}\text { holding cost with energy effect of product } i \\
\text { (\$/unit/unit time), } C_{h_{i}}=\left(C_{h_{1_{i}}}+C_{h_{1_{i}}}^{\prime}\right)+\left(C_{h_{2_{i}}}+C_{h_{2_{i}}}^{\prime}\right) t\end{array}$ \\
\hline$D_{i}$ & demand for product $i, D_{i}=a e^{b t}+\frac{p_{\max }-p_{i}}{p_{i}-p_{\min }}$ \\
\hline$S_{i}(t)$ & $\begin{array}{l}\text { time-dependent production rate under the optimum energy effect } \\
\text { for product } i\end{array}$ \\
\hline$\Omega_{1}$ & total profit under the effect of energy and carbon footprint per cycle $(\$ /$ cycle) \\
\hline$\Omega_{2}$ & $\begin{array}{l}\text { total profit under the effect of energy as well as carbon footprint, inflation, } \\
\text { and time-value of money ( } \$ / \text { cycle) }\end{array}$ \\
\hline$\Omega_{3}$ & final total profit per cycle of the MSEEEMQ (\$/cycle) \\
\hline
\end{tabular}

Those above mentioned notation is utilized for the proposed model.

\subsection{Assumptions}

The following assumptions are considered to develop this model.

1. This model considers a sustainable economic energy efficient reliable manufacturing quantity model (SEEERMQ) for a multi-item in an imperfect production system.

2. During a long-run production process, the system moves to an out-of-control state from an in-control state and it starts to produce some defective items. The production of defective items is a very small percentage of production rate as the industry manager always maintains a reliable system. For maintaining the brand image of a company, a whole-lot-inspection policy is utilized to sperate 
the defective items. The defective items are reworked under optimum energy consumption with a fixed cost to make them as new (Sarkar [26], Sarkar et al. [27], San-Jośe et al. [28]).

3. For the reliable energy efficient production system, the management of the industry has two choices; invest more funds to increase the system reliability under optimum energy or maintain the whole system in such a way that the failure rate with the optimum energy can be reduced. Therefore, the system design variable for $\eta$ is defined as follows:

$$
\eta=\frac{\text { Numbers of failures }}{\text { Total number of working hours }}
$$

i.e., less number of failure indicates a more reliable system. The industry managers use this opportunity to make the system reliable by reducing the failure rate of the production system to make a sustainable EMQ (Sarkar [29], Shin et al. [30], Cárdenas-Barrón et al. [31]).

4. As this is a multi-item energy efficient production system, the holding cost is different for different items depending on time linearly. The demand of a multi-item is assumed as time and selling-price dependent (Manente et al. [32], Govindan et al. [33], Sarkar et al. [34]).

5. The development cost under optimum energy is considered as a function of a system design variable and the corresponding unit production cost of the system under the optimum energy consumption is dependent on the development cost, material cost, and tool/die cost. All costs are related to optimum energy consumption (Sarkar et al. [35], Govindan et al. [36]).

6. The inflation and time-value of money are considered to obtain profits. The time horizon is considered as finite and the initial inventory, as well as the final inventory, are zero at the initial and final boundary points.

\section{Optimization Problem Development}

This section contains a mathematical model, solution of the optimization problem and verification of the optimality conditions.

\subsection{Mathematical Model}

To make a multi-item sustainable economic energy efficient reliable manufacturing quantity (MSEEERMQ) model, it is essential to make the manufacturing system sustainable and reliable under efficient energy system. For making sustainable manufacturing system, it should pass through an effective energy and a reduced carbon footprint environment, the optimum profit, and the best social effect whereas for making a reliable manufacturing system, $i$ the manufacturing system should consistently produce quality items without any defective products. Hence, the combination of these two systems gives a sustainable economic energy efficient reliable manufacturing system. Therefore, the aim of the model is three-fold: make the manufacturing system energy efficient sustainable, continue with system reliability, and obtain the optimum profit. For making a sustainable energy efficient manufacturing system, a basic economic manufacturing quantity model is taken where the manufacturing cost is dependent on system development cost under the energy and carbon footprint consideration and production rate. The development cost $(D C)$ under the efficient energy and carbon footprint of the manufacturing system is as follows:

$$
D C=A+A^{\prime}+B e^{\frac{k\left(\eta_{\max }-\eta\right)}{\left(\eta-\eta_{\min }\right)}},
$$

where $\eta$ is the system design variable, which is an indicator of system reliability. The development cost is the summation of initial development cost, energy and carbon footprint cost, and reliability related cost.

Using this development cost per product, the unit production cost (UPC) under the optimum energy and carbon footprint can be found as the summation of material cost, energy and carbon 
footprint cost, development cost per product, and tool/die cost, where $S_{i}(t)$ is the time-dependent production rate.

$$
U P C=C_{0_{i}}+C_{0_{i}}^{\prime}+\frac{A+A^{\prime}+B e^{\frac{k(\eta \max -\eta)}{\left(\eta-\eta_{\min }\right)}}}{S_{i}(t)}+\alpha S_{i}(t) .
$$

Therefore, the total production cost (TPC) under the effective energy per cycle is given by

$$
\begin{aligned}
T P C & =\int_{0}^{T} S_{i}(t) U P C d t \\
& =\int_{0}^{T}\left[C_{O_{i}}+C_{0_{i}}^{\prime}+\frac{A+A^{\prime}+B e^{\frac{k\left(\eta_{\max }-\eta\right)}{\left(\eta-\eta_{\min }\right)}}}{S_{i}(t)}+\alpha S_{i}(t)\right] S_{i}(t) d t .
\end{aligned}
$$

Therefore, for the sustainable energy efficient manufacturing system, the governing differential equation of inventory can be written as

$$
\frac{d Q_{i}(t)}{d t}=S_{i}(t)-D_{i}(t)
$$

where the rate of change of the production quantity is equal to the difference between time-dependent production rate and time-dependent demand.

Therefore, the production rate $S_{i}(t)$ can be found from Equation (5) as

$$
S_{i}(t)=\frac{d Q_{i}(t)}{d t}+D_{i}(t)
$$

As the product is holding for a long time by using the optimum energy carbon footprint, it is found from the old data, that the holding cost is linearly varying with time. The holding cost $(H C)$ under the efficient energy and carbon footprint of the manufacturing system is given as follows:

$$
H C=\int_{0}^{T}\left[C_{h_{1_{i}}}+C_{h_{1_{i}}}^{\prime}+C_{h_{2_{i}}} t+C_{h_{2_{i}}}^{\prime} t\right] Q_{i} d t
$$

where $C_{h_{1_{i}}}$ is the constant holding cost per unit time and $C_{h_{1_{i}}}^{\prime}$ is the constant energy and carbon footprint cost due to holding cost; $C_{h_{2_{i}}}$ and $C_{h_{2_{i}}}^{\prime}$ are similar cost but varies with time.

Due to maintaining the brand image of the manufacturing company, they arrange a full-lot inspection policy for all lots of produced products under optimum energy. Therefore, the inspection cost $(I C)$ of the whole produced lot $\left(Q_{i}\right)$, under the optimal energy and carbon footprint utilized, is given by

$$
I C=\int_{0}^{T}\left(C_{i}+C_{i}^{\prime}\right) Q_{i} d t
$$

To make more profit, from the previous data, it is found that the demand is dependent on time and selling price both, that is, if the time is increased then the demand is increasing exponentially, whereas if price is decreasing, then demand is increasing. Therefore, the demand is taken as

$$
D_{i}\left(t, p_{i}\right)=a e^{b t}+\frac{p_{\max }-p_{i}}{p_{i}-p_{\min }}
$$

where $a$ and $b$ are the scaling and shape parameters for exponentially time-dependent demand, respectively. $p_{i}$ is the selling price with its maximum as $p_{\max }$ and minimum as $p_{\min }$.

During the production system, the manufacturing system moves to an out-of-control state from an in-control state and the defective items are produced in a rate $\xi e^{\eta t}$, where $\xi$ is a scaling parameter. 
Hence, the total defective items during time $t$ is $\xi^{\eta} e^{\eta t} S_{i}(t)$. The reworking cost $(R C)$ of those defective items with the minimum energy consumption and reduced carbon footprint is given by

$$
R C=\int_{0}^{T}\left(C_{d_{i}}+C_{d_{i}}^{\prime}\right) \xi e^{\eta t} S_{i}(t) d t,
$$

where the rework cost and energy as well as carbon footprint cost per product is $C_{d_{i}}$ and $C_{d_{i}}^{\prime}$ under the time dependent production rate $S_{i}(t)$.

The profit of the whole MSEEERMQ under the effective energy and carbon footprint cost is

$$
\begin{aligned}
\Omega_{1}(\eta)= & \int_{0}^{T}\left[\left(p_{i}-\left(\left(C_{0_{i}}+C_{0_{i}}^{\prime}\right)+\frac{\left(A+A^{\prime}\right)+B e^{\frac{k(\eta \max -\eta)}{\left(\eta-\eta_{\min }\right)}}}{S_{i}(t)}+\alpha S_{i}(t)\right)\right) S_{i}(t)\right. \\
& \left.-\left(\left(C_{h_{1_{i}}}+C_{h_{1_{i}}}^{\prime}\right)+\left(C_{h_{2_{i}}}+C_{h_{2_{i}}}^{\prime}\right) t\right) Q_{i}-\left(C_{d_{i}}+C_{d_{i}}^{\prime}\right) e^{\eta t} \xi S_{i}(t)-\left(C_{i}+C_{i}^{\prime}\right) Q_{i}\right] d t .
\end{aligned}
$$

The first term of the equation, $\int_{0}^{T} p_{i} S_{i}(t) d t$, is the revenue of the MSEEERMQ system. The second term, $\int_{0}^{T}\left(\left(C_{0_{i}}+C_{0_{i}}^{\prime}\right)+\frac{\left(A+A^{\prime}\right)+B e^{\frac{k(\eta \max -\eta)}{\left(\eta-\eta_{\min }\right)}}}{S_{i}(t)}+\alpha S_{i}(t)\right) S_{i}(t) d t$ consists of material cost, development cost, tool/die cost along with the corresponding energy and carbon footprint costs. The third term is the constant and variable holding costs and its energy and carbon footprint costs. $\int_{0}^{T}\left(C_{d_{i}}+C_{d_{i}}^{\prime}\right) e^{\eta t} \xi S_{i}(t) d t$ is the reworking cost along with its energy and carbon footprint cost. The last term is the inspection cost and its energy consumption cost.

Based on the previous data, it is found that the inflation rate and time-value of money are most important effective function for every cost (see for reference Govindan et al. [37]). Therefore, under inflation and time-value of money, the total profit can be calculated using Equations (6), (9) and (11)

$$
\begin{aligned}
\Omega_{2}(\eta)= & \text { Revenue under inflation-material cost with energy and carbon footprint } \\
& \text { cost under inflation }- \text { rework cost for defective product with energy } \\
& \text { and carbon footprint cost under inflation } \\
- & \text { tool/die cost with energy and carbon footprint cost under inflation } \\
- & \text { holding cost with energy and carbon footprint cost under inflation } \\
- & \text { inspection cost with energy and carbon footprint cost under inflation } \\
- & \text { development cost with energy and carbon footprint cost under inflation } \\
= & \int_{0}^{T} e^{-\tau t}\left[( \dot { Q } _ { i } + a e ^ { b t } + \frac { p _ { \operatorname { m a x } } - p _ { i } } { p _ { i } - p _ { \operatorname { m i n } } } ) \left(p_{i}-\left(C_{0_{i}}+C_{0_{i}}^{\prime}\right)\right.\right. \\
& \left.-\left(C_{d_{i}}+C_{d_{i}}^{\prime}\right) e^{\eta t} \xi\right)-\alpha\left(\dot{Q}_{i}+a e^{b t}+\frac{p_{\max }-p_{i}}{p_{i}-p_{\min }}\right)^{2} \\
& \left.-Q_{i}\left(C_{h_{1_{i}}}+C_{h_{2_{i}}} t+C_{i}+C_{i}^{\prime}\right)-A-B e^{\frac{k(\eta \max -\eta)}{\left(\eta-\eta_{\min }\right)}}\right] d t \\
= & \int_{0}^{T} F\left(Q_{i}, \dot{Q}_{i}, t\right) d t
\end{aligned}
$$


where

$$
\begin{aligned}
F\left(Q_{i}, \dot{Q}_{i}, t\right)= & e^{-\tau t}\left[( \dot { Q } _ { i } + a e ^ { b t } + \frac { p _ { \operatorname { m a x } } - p _ { i } } { p _ { i } - p _ { \operatorname { m i n } } } ) \left(\left(p_{i}+p_{i}^{\prime}\right)-\left(C_{0_{i}}+C_{0_{i}}^{\prime}\right)\right.\right. \\
& \left.-\left(C_{d_{i}}+C_{d_{i}}^{\prime}\right) e^{\eta t} \xi\right)-\alpha\left(\dot{Q}_{i}+a e^{b t}+\frac{p_{\max }-p_{i}}{p_{i}-p_{\min }}\right)^{2} \\
& \left.-Q_{i}\left(C_{h_{1_{i}}}+C_{h_{2_{i}}} t+C_{i}+C_{i}^{\prime}\right)-A-B e^{\frac{k(\eta \max -\eta)}{\left(\eta-\eta_{\min }\right)}}\right] .
\end{aligned}
$$

To make the model sustainable, energy and carbon footprint cost are considered within the model. Hence, the final profit of the multi-item sustainable economic energy efficient reliable manufacturing quantity model under carbon footprint and energy consumption is given by

$$
\begin{aligned}
\Omega_{3}(\eta) & =\int_{0}^{T} e^{-\tau t}\left[\left(\dot{Q}_{i}+a e^{b t}+\frac{p_{\max }-p_{i}}{p_{i}-p_{\min }}\right)\left(p_{i}-\left(C_{o_{i}}+C_{o_{i}}^{\prime}\right)-\left(C_{d_{i}}+C_{d_{i}}^{\prime}\right) e^{\eta t} \xi\right)\right. \\
& -\alpha\left(\dot{Q}_{i}+a e^{b t}+\frac{p_{\max }-p_{i}}{p_{i}-p_{\min }}\right)^{2}-Q_{i}\left(C_{h_{1_{i}}}+C_{h_{1 i}}^{\prime}+C_{n_{2_{i}}} t+C_{h_{2 i}}^{\prime} t+C_{i}+C_{i}^{\prime}\right) \\
& \left.-\left(A+A^{\prime}\right)-B e^{\frac{k(\eta \max -\eta)}{\left(\eta-\eta_{\min }\right)}}\right] d t .
\end{aligned}
$$

\subsection{Solution for Optimization Problem}

For the maximum profit, the simplified form of the profit can be written as

$$
\begin{aligned}
\Omega_{3}(\eta)= & Y_{4}+\left\{\frac{m_{1} m_{2}\left(\eta+\frac{\tau}{2 \alpha}\right)}{(\eta-\tau)^{2}}+\frac{m_{2} X_{4}}{\tau(\eta-\tau)}\right\}\left(e^{(\eta-\tau) T}-1\right)-\frac{m_{2} \tau N}{n}\left(e^{\eta T}-1\right) \\
& -\left\{\frac{m_{2} a\left(\tau+\frac{b}{2 \alpha}\right)}{(b-\tau)(b-\tau+\eta)}+\frac{m_{2} a b}{b-\tau+\eta}\right\}\left(e^{(b-\tau+\eta) T}-1\right) \\
& -\frac{m_{2}^{2}\left(\eta+\frac{\tau}{2 \alpha}\right)}{(\eta-\tau)(2 \eta-\tau)}\left(e^{(2 \eta-\tau) T}-1\right)-\alpha\left[\frac{m_{2}^{2}\left(\eta+\frac{\tau}{2 \alpha}\right)^{2}}{(\eta-\tau)^{2}(2 \eta-\tau)}\left(e^{(2 \eta-\tau) T}-1\right)\right. \\
& \left.+\frac{2 m_{2} m_{3}\left(\eta+\frac{\tau}{2 \alpha}\right)}{(\eta-\tau)}(b+\eta-\tau)\left(e^{(b+\eta-\tau) T}-1\right)-\frac{2 m_{2} x_{4}\left(\eta+\frac{\tau}{2 \alpha}\right)}{\tau(\eta-\tau)^{2}}\left(e^{(\eta-\tau) T}-1\right)\right] \\
& -\frac{m_{7} m_{2}\left(\eta+\frac{\tau}{2 \alpha}\right)}{\eta(\eta-\tau)}\left(e^{(\eta-\tau) T}-1\right)-\frac{m_{8} m_{2}\left(\eta+\frac{\tau}{2 \alpha}\right)}{\eta(\eta-\tau)}\left\{\frac{T e^{(\eta-\tau) T}}{\eta-\tau}\right. \\
& \left.-\frac{1}{(\eta-\tau)^{2}}\left(e^{(\eta-\tau) T}-1\right)\right\}+\frac{B e^{\left.\frac{k(\eta \max }{\eta-\eta}-\eta\right)}}{\tau}\left(e^{-\tau T}-1\right),
\end{aligned}
$$

(please see Appendix A for detailed calculations).

For using the necessary condition, differentiating the profit equation one can write

$$
\frac{d \Omega_{3}(\eta)}{d \eta}=F_{1}(\eta)+F_{2}(\eta)+F_{3}(\eta)+F_{4}(\eta)+F_{5 g}(\eta)
$$

(please see Appendix B for values of $F_{1}(\eta), F_{2}(\eta), F_{3}(\eta), F_{4}(\eta)$ and $F_{5 g}(\eta)$ ).

The existence of the maximum value of the profit function under the effect of optimum energy through a lemma.

Lemma 1. The profit of the whole multi-item sustainable economic energy efficient reliable manufacturing quantity model has its maximum value during the time interval $[0, T]$. 
Proof. To calculate the optimal path with optimum energy consumption and proper carbon footprint, one can assume two curves $C_{g}$ and $C_{l}$, where the profit of the whole multi-item sustainable economic energy efficient reliable manufacturing quantity will be the maximum through the curve $C_{g}$ and $C_{l}$ is any other curve. Now, as for $C_{g}$, the profit under carbon footprint and optimum energy is maximum, thus, one can consider the curve $C_{g}$ can be defined by

$$
Q_{i}(t)=Q_{i \gamma}(t) ; t \in[0, T],
$$

and the curve $C_{l}$ can be defined as

$$
Q_{i}(t)=Q_{i l}(t)=Q_{i \gamma}(t)+l u(t) ; t \in[0, T],
$$

where $u(t)$ is any differentiable function with respect to time $t$ and $l$ is very small quantity. Hence, the profit of the whole multi-item sustainable economic energy efficient reliable manufacturing quantity model under carbon footprint and optimum energy can be found by

$$
\Omega_{3}(l)=\int_{0}^{T} v_{l} d t, \text { where } v_{l}=v\left(Q_{i \gamma}(t)+l u(t), \dot{Q}_{i \gamma}(t)+l \dot{u}(t), t\right) .
$$

From, the necessary condition of the classical optimization, it can be found that the rate of change of profit under carbon footprint and optimum energy with respect to $l$ is zero as follows:

$$
\left.\frac{d \Omega_{3}(l)}{d l}\right|_{l=0}=0 .
$$

Therefore, from Equation (19), one can find that

$$
\begin{aligned}
\frac{d \Omega_{3}(l)}{d l} & =\int_{0}^{T}\left\{u(t) \frac{\partial v_{l}}{\partial Q_{i}}+\dot{u}(t) \frac{\partial v_{l}}{\partial \dot{Q}_{i}}\right\} d t \\
& =\left[u(t) \frac{\partial v_{l}}{\partial \dot{Q}_{i}}\right]_{0}^{T}+\int_{0}^{T} u(t)\left\{\frac{\partial v_{l}}{\partial Q_{i}}-\frac{d}{d t}\left(\frac{\partial v_{l}}{\partial \dot{Q}_{i}}\right)\right\} d t \\
& =\int_{0}^{T} u(t)\left\{\frac{\partial v_{l}}{\partial Q_{i}}-\frac{d}{d t}\left(\frac{\partial v_{l}}{\partial \dot{Q}_{i}}\right)\right\} d t .
\end{aligned}
$$

As $Q_{i}(t)$ is fixed at both end points during $[0, T]$, hence the arbitrary function $u(t)$ must be zero at the end points. Hence, equating $\left.\frac{d \Omega_{3}(l)}{d l}\right|_{l=0}=0$ gives

$$
\frac{\partial v_{l}}{\partial Q_{i}}-\frac{d}{d t}\left(\frac{\partial v_{l}}{\partial \dot{Q}_{i}}\right)=0
$$

This Equation [22] represents the necessary conditions of the profit of the whole multi-item sustainable economic energy efficient reliable manufacturing quantity model. Therefore, differentiating $\frac{d \Omega_{3}(l)}{d l}$ with respect to $l$, one can find

$$
\frac{d^{2} \Omega_{3}(l)}{d l^{2}}=\int_{0}^{T}\left\{u(t)^{2} \frac{\partial^{2} v_{l}}{\partial Q_{i}{ }^{2}}+2 u(t) \dot{u}(t) \frac{\partial^{2} v_{l}}{\partial Q_{i} \dot{Q}_{i}}+\left\{\dot{u}_{i}\right\}^{2} \frac{\partial^{2} v_{l}}{\partial \dot{Q}_{i}{ }^{2}}\right\} d t
$$


Therefore, to calculate the optimal curve, differentiating $v$ partially with respect to $Q_{i}(t)$ and $\dot{Q}_{i}(t)$, one can find

$$
\begin{aligned}
\frac{\partial v}{\partial Q_{i}} & =e^{-\tau t}\left[C_{h_{1_{i}}}+C_{h_{1_{i}}}^{\prime}+C_{h_{2_{i}}}+C_{h_{2_{i}}}^{\prime}+C_{i}+C_{i}^{\prime}\right], \\
\frac{\partial^{2} v}{\partial Q_{i}^{2}} & =0, \\
\frac{\partial v}{\partial \dot{Q}_{i}} & =e^{-\tau t}\left[\left(p_{i}-C_{0_{i}}-C_{0_{i}}^{\prime}-C_{d_{i}} e^{\eta t} \xi-C_{d_{i}}^{\prime} e^{\eta t} \xi\right)\right. \\
& \left.-2 \alpha\left(\dot{Q}_{i}+a e^{b t}+\frac{p_{\max }-p_{i}}{p_{i}-p_{\min }}\right)\right], \\
\frac{\partial^{2} v}{\partial \dot{Q}_{i}^{2}} & =-2 \alpha e^{-\tau t}, \\
\frac{\partial^{2} v}{\partial Q_{i} \partial \dot{Q}_{i}} & =0 .
\end{aligned}
$$

Now, at the point $l=0$, one can obtain

$$
\begin{aligned}
\left.\frac{d^{2} \Omega_{3}(l)}{d l^{2}}\right|_{l=0} & =\int_{0}^{T}\left\{u(t)^{2} \frac{\partial^{2} v_{l}}{\partial Q_{i}{ }^{2}}+2 u(t) \dot{u}(t) \frac{\partial^{2} v_{l}}{\partial Q_{i} \dot{Q}_{i}}+\left\{\dot{u}_{i}\right\}^{2} \frac{\partial^{2} v_{l}}{\partial \dot{Q}_{i}{ }^{2}}\right\} d t \\
& =\int_{0}^{T}-2 \alpha e^{-\tau t}\left\{\dot{u}_{i}\right\}^{2} d t<0 .
\end{aligned}
$$

Hence, this proves sufficient conditions for the whole profit of multi-item sustainable economic energy efficient reliable manufacturing quantity model under carbon footprint and optimum energy has a global maximum value within the interval $[0, T]$. This completes the proof.

For obtaining the optimum curve, from Euler-Lagrange equation, one can write

$$
\begin{gathered}
\frac{d}{d t}\left(\frac{\partial v}{\partial \dot{Q}_{i}}\right)-\frac{\partial v}{\partial Q_{i}}=0 \\
\Rightarrow \frac{d}{d t}\left[e^{-\tau t}\left[\left(p_{i}-C_{0_{i}}-C_{0_{i}}^{\prime}-C_{d_{i}} e^{\eta t} \xi-C_{d_{i}}^{\prime} e^{\eta t} \xi\right)-2 \alpha\left(\dot{Q}_{i}+a e^{b t}+\frac{p_{\text {max }}-p_{i}}{p_{i}-p_{\min }}\right)\right]\right] \\
-e^{-\tau t}\left[C_{h_{1_{i}}}+C_{h_{1_{i}}}^{\prime}+C_{h_{2_{i}}}+C_{h_{2_{i}}}^{\prime}+C_{i}+C_{i}^{\prime}\right]=0 \\
\Rightarrow \quad \ddot{Q}_{i}-\tau \dot{Q}_{i}=X_{3}+X_{4}
\end{gathered}
$$

(the values of $X_{3}$ and $X_{4}$ are given in Appendix A).

By solving the Equation (31) it can be obtained

$$
Q_{i}(t)=M_{i}+N_{i} e^{\tau t}+\frac{a\left(\tau+\frac{b}{2 \alpha}\right) e^{b t}}{b(b-\tau)}+\frac{\left(C_{d_{i}}+C_{d_{i}}^{\prime}\right) \xi e^{\eta t}\left(\eta+\frac{\tau}{2 \alpha}\right)}{\eta(\eta-\tau)}-\frac{t}{\tau} X_{4} .
$$


Using $Q_{i}(0)=0$ and $Q_{i}(T)=0$, it can be obtained

$$
\begin{aligned}
M_{i} & =\frac{1}{\left(1-e^{\tau T}\right)}\left[\frac{T X_{4}}{\tau}+\frac{a\left(\tau+\frac{b}{2 \alpha}\right)\left(e^{\tau T}-e^{b T}\right)}{b(b-\tau)}+\frac{\left(C_{d_{i}}+C_{d_{i}}^{\prime}\right) \xi\left(e^{\tau T}-e^{\eta T}\right)\left(\eta+\frac{\tau}{2 \alpha}\right)}{\eta(\eta-\tau)}\right] \\
\text { and } N_{i} & =\frac{1}{\left(e^{\tau T}-1\right)}\left[\frac{T X_{4}}{\tau}+\frac{a\left(\tau+\frac{b}{2 \alpha}\right)\left(1-e^{b T}\right)}{b(b-\tau)}+\frac{\left(C_{d_{i}}+C_{d_{i}}^{\prime}\right) \xi\left(1-e^{\eta T}\right)\left(\eta+\frac{\tau}{2 \alpha}\right)}{\eta(\eta-\tau)}\right] .
\end{aligned}
$$

Hence, the rate of changes of inventory and production rate can be found as

$$
\begin{aligned}
\dot{Q}_{i}(t)= & \sum_{i=1}^{n}\left[\tau N_{i} e^{\tau t}+\frac{a\left(\tau+\frac{b}{2 \alpha}\right) e^{b t}}{(b-\tau)}+\frac{\left(C_{d_{i}}+C_{d_{i}}^{\prime}\right) \xi e^{\eta t}\left(\eta+\frac{\tau}{2 \alpha}\right)}{(\eta-\tau)}-\frac{X_{4}}{\tau}\right] \\
\text { and } \dot{S}_{i}(t)= & \sum_{i=1}^{n} \dot{Q}(t)+\sum_{i=1}^{n} D_{i} \\
= & \sum_{i=1}^{n}\left[\tau N_{i} e^{\tau t}+\frac{a\left(\tau+\frac{b}{2 \alpha}\right) e^{b t}}{(b-\tau)}+\frac{\left(C_{d_{i}}+C_{d_{i}}^{\prime}\right) \xi e^{\eta t}\left(\eta+\frac{\tau}{2 \alpha}\right)}{(\eta-\tau)}-\frac{X_{4}}{\tau}\right. \\
& \left.+a e^{b t}+\frac{p_{\max }-p_{i}}{p_{i}-p_{\text {min }}}\right] .
\end{aligned}
$$

Hence, using Equation (36), the profit becomes

$$
\Omega_{3}(\eta)=\sum_{i=1}^{n} \int_{0}^{T} e^{-\tau t} X_{8} d t-\frac{X_{7}\left(1-e^{-\tau T}\right)}{\tau} .
$$

The verification of the global optimality under the optimum energy can be done by Lemma 2 .

\subsection{Verification of Optimality Condition}

The verification of optimality is proved by Lemma 2 .

Lemma 2. If the first order derivative of profit of multi-item sustainable economic energy efficient reliable manufacturing quantity model is less than zero at $\eta=\eta_{\max }$ then $\frac{d \Omega_{3}(\eta)}{d \eta}$ must have a solution within $\left[\eta_{\text {min }}, \eta_{\text {max }}\right]$; otherwise $\frac{d \Omega_{3}(\eta)}{d \eta}=0$ may or may not have an optimum solution within $\left[\eta_{\min }, \eta_{\text {max }}\right]$. The maximum value of the profit of multi-item sustainable economic energy efficient reliable manufacturing quantity model exists if $\frac{d^{2} \Omega_{3}(\eta)}{d \eta^{2}}<0$ at the optimum value of $\eta^{*}$.

Proof. For calculation of the maximum profit of multi-item sustainable economic energy efficient reliable manufacturing quantity model, differentiating $\Omega_{3}(\eta)$ with respect to $\eta$ two times.

Simplifying and differentiating with respect to $\eta$, one can have

$$
\frac{d \Omega_{3}(\eta)}{d \eta}=\frac{k\left(1-e^{-\tau t}\right)}{\tau} B e^{\frac{k(\eta \max -\eta)}{\left(\eta-\eta_{\min }\right)}} \frac{\left(\eta_{\max }-\eta_{\min }\right)}{\left(\eta-\eta_{\min }\right)},
$$

which can be further differentiated with respect to $\eta$, it can be found

$$
\begin{aligned}
\frac{d^{2} \Omega_{3}(\eta)}{d \eta^{2}} & =-\frac{k\left(1-e^{-\tau t}\right)}{\tau} B e^{\frac{k\left(\eta_{\max }-\eta\right)}{\left(\eta-\eta_{\min }\right)}} \frac{\left(\eta_{\max }-\eta_{\min }\right)}{\left(\eta-\eta_{\min }\right)^{2}}\left[1+\frac{k\left(\eta_{\max }-\eta\right)}{\left(\eta-\eta_{\min }\right)}\right] \\
& <0 .
\end{aligned}
$$


As $\lim _{\eta \rightarrow \eta_{\min }} \frac{d \Omega_{3}(\eta)}{d \eta} \rightarrow \infty$, hence $\frac{d \Omega_{3}(\eta)}{d \eta}$ must have at least one solution provided $\frac{d \Omega_{3}\left(\eta_{\max }\right)}{d \eta}<0$ is satisfied; otherwise $\frac{d \Omega_{3}(\eta)}{d \eta}=0$ may or may not have any optimum solution within $\left[\eta_{\min }, \eta_{\max }\right]$. As $\frac{d^{2} \Omega_{3}(\eta)}{d \eta^{2}}<0$, hence $\Omega_{3}\left(\eta^{*}\right)$ has the maximum value at $\eta=\eta^{*}$ within $\left[\eta_{\min }, \eta_{\max }\right]$. This completes the proof.

\section{Numerical Experiment}

This section shows the numerical examples and sensitivity analysis of the key parameters of the study.

\subsection{Numerical Example}

There are three numerical examples described below.

Example 1. For numerical experiment, the data is taken from an existing paper (Sana, [2]). For this experiment, Mathematica 10 is utilized as an optimization tool, where the computer is Intel CORE i5, 4 GB RAM. The illustrative example is given as follows:

A MSEEERMQ model is considered for a numerical study, where the demand pattern $D_{i}=150 e^{2 t}+$ $\frac{p_{\max }-p_{i}}{p_{i}-p_{\min }}$ and cycle length $(T)$ is 0.33 years. The management decides the maximum value of products as $\$ 350$ per product and the minimum value $\$ 10$ per product, whereas the optimum prices are decided by the management as $\$ 50$ and $\$ 40$ for two products, respectively. To hold these products for small timing in manufacturing house the constant holding costs are as $\$ 0.8$ and $\$ 1.2$ per unit product per year and the variable holding costs are $\$ 1.5$ and $\$ 1.1$ per unit product per year whereas the corresponding constant energy and carbon footprint costs are $\$ 0.2$ and $\$ 0.3$ per unit product per year as well as the variable energy consumption and carbon footprint costs are $\$ 0.5$ and $\$ 0.4$ per unit product per year. To develop two products, the basic raw material costs $\left(C_{0_{1}}\right.$ and $\left.C_{0_{2}}\right)$ are $\$ 2.5$ per unit and $\$ 3$ per unit, respectively. The corresponding energy and carbon footprint costs to transfer those raw material into the material before using in production system are $\left(C_{0_{1}}^{\prime}\right.$ and $\left.C_{0_{2}}^{\prime}\right)$ are $\$ 0.5$ per unit and $\$ 1$ per unit, respectively. The fixed development costs $\left(A_{1}\right.$ and $\left.A_{2}\right)$ for two products are $\$ 4.5$ and $\$ 5.5$ per product, respectively and the corresponding energy and carbon footprint cost is $\left(A_{1}^{\prime}\right.$ and $\left.A_{2}^{\prime}\right) \$ 0.5$ for each product whereas the tool/die cost $(\alpha)$ is $\$ 0.1$ per unit. The scaling parameter for the design variable $(k)$ is 0.5 . The cost parameter $\left(\beta_{i}\right)$ for the system design change is $\$ 3.5$ and $\$ 3$ per product whereas the probability of the maximum value of the failure rate is 0.9 and the probability of the minimum value of the failure rate is 0.1 . The defective rate of production is $\xi e^{\eta t}$, where the scaling parameter $\xi=0.1$. The inspection costs for two products $\left(C_{1}\right.$ and $\left.C_{2}\right)$ are $\$ 0.5$ and $\$ 0.4$ per product. To repair those defective products, a rework cost $\left(C_{d_{i}}\right)$ is utilized. Thus, the rework costs $\left(C_{d_{1}}\right.$ and $\left.C_{d_{2}}\right)$ for two products are $\$ 3.8$ and $\$ 0.7$ per unit and energy consumption and carbon footprint costs $\left(C_{d_{1}}^{\prime}\right.$ and $\left.C_{d_{2}}^{\prime}\right)$ are $\$ 0.2$ and $\$ 0.3$. For the calculation of profit, the inflation rate $(\tau)$ is considered $1 \%(0.01)$.

The global maximum profit can be found at $\eta=0.104$ and the maximum profit is $\Omega_{3}(\eta)=\$ 2745.22 /$ cycle. It means that within a cycle, the number of failures is less, which is obtained for the proposed model under energy consumption and carbon footprint with the maximum profit $\$ 2745.22$ per cycle.

Example 2. Within the data of Example 1, the value of the cycle length $T=0.33$ time unit is changed to a $T=0.25$ time unit; all other parameter value are the same. The optimum result is found as the maximum profit $\$ 2043.22$ per cycle and the reliability design variable $\eta=0.17$, which means the production system is less reliable than Example 1 and less profitable. Therefore, it can be concluded that the management should maintain less cycle length to maintain the reliable sustainable production system.

Example 3. If the inflation rate $(\tau)$ increases from $1 \%$ to $2 \%$ and all other data is the same as Example 1, then the global maximum profit $\Omega_{3}(\eta)=\$ 2668.75$ per cycle and the failure rate $(\eta)=0.21$. It means that with the increasing value of the inflation rate, the profit is reduced and the production system's reliability is reduced as the failure rate increases. 


\subsection{Sensitivity Analysis}

The sensitivity analysis of key parameters of Example 1 are considered and major findings can be concluded from the sensitivity analysis Table 3. Only some chosen parameters are written here as changes in the rest of the parameters are found negligible with a high percentage. Thus, the most sensitive parameters are taken for sensitive analysis.

Table 3. Sensitivity analysis for expected total cost.

\begin{tabular}{cccccc}
\hline Parameters & Changes (in \%) & $\Omega_{\mathbf{3}}(\boldsymbol{\eta}) \mathbf{( \% )}$ & Parameters & Changes (in \%) & $\Omega_{\mathbf{3}}(\boldsymbol{\eta}) \mathbf{( \% )}$ \\
\hline & $-50 \%$ & +0.003 & & $-50 \%$ & +0.006 \\
$C_{h_{h_{1}}}$ & $-25 \%$ & +0.002 & & $-25 \%$ & +0.003 \\
& $+25 \%$ & -0.002 & $C_{1}$ & $+25 \%$ & -0.003 \\
& $+50 \%$ & -0.003 & & $+50 \%$ & -0.008 \\
\hline \multirow{6}{*}{$C_{h_{1_{2}}}$} & $-50 \%$ & +0.006 & & $-50 \%$ & 0.01 \\
& $-25 \%$ & +0.003 & & $-25 \%$ & +0.006 \\
& $+25 \%$ & -0.003 & $C_{2}$ & $+25 \%$ & -0.007 \\
& $+50 \%$ & -0.006 & & $+50 \%$ & -0.01 \\
\hline$C_{h_{2}}$ & $-50 \%$ & -0.04 & & $-50 \%$ & -63.09 \\
& $-25 \%$ & -0.02 & & $-25 \%$ & -30.11 \\
& $+25 \%$ & +0.02 & $P_{1}$ & $+25 \%$ & +29.48 \\
& $+50 \%$ & +0.04 & & $+50 \%$ & +58.65 \\
\hline$C_{h_{22}}$ & $-50 \%$ & -0.03 & & $-50 \%$ & -55.79 \\
& $-25 \%$ & -0.01 & & $-25 \%$ & -25.21 \\
& $+25 \%$ & +0.01 & $P_{2}$ & $+25 \%$ & +31.66 \\
& $+50 \%$ & +0.03 & & $+50 \%$ & +51.66 \\
\hline$C_{0_{1}}$ & $-50 \%$ & +3.59 & & $-50 \%$ & +4.87 \\
& $-25 \%$ & +1.79 & & $-25 \%$ & +2.43 \\
& $+25 \%$ & -0.86 & $C_{0_{2}}$ & $+25 \%$ & -2.43 \\
& $+50 \%$ & -2.92 & & $+50 \%$ & -4.87 \\
\hline
\end{tabular}

1. With the increase of constant holding cost, the profit for both items decrease. The changes of profit are almost the same for both positive and negative changes of constant holding. Thus, it can be said that constant holding costs are less sensitive for both the items. If the energy and carbon footprint cost are increasing (which is related to the constant holding cost), the profit is decreasing too as there is no way to reduce this extra cost. Therefore, the management should take care of the amount of energy consumption even though it is less sensitive but important.

2. In case of the time-dependent holding cost, the profit is directly proportional to the cost and the corresponding energy and carbon footprint cost for both products. Thus, it can be concluded that the time-dependent holding costs show a reverse impact of constant holding cost on profit. To maintain the sustainable issue, this energy consumption and carbon footprint cost with respect to time should be maintained properly.

3. The positive changes of material costs have a negative effect on profit for both single and double items. The decreasing percentage of material cost is more effective than positive changes for single items. For both items, the percentage change of both negative and positive changes are the same. It is quite natural that the raw material's price increasing value gives less profit, but there is a consumption of energy and carbon footprint cost related to the preparation of raw material before production. If high quality raw material is utilized and the price is increased, there is a change for the reduction of energy consumption and carbon footprint for good quality raw material. Therefore, although the raw material prices increase, the profit will not be reduced by a huge amount.

4. Selling prices of two products have a huge impact on profit for both the items. The negative changes of selling prices are more sensitive than positive changes for both items. It can be found 
that selling-price is most sensitive in this study. The analysis of the major key parameters are given and more analyses are not given as those are less sensitive compared to these parameters.

\section{Conclusions}

The study obtained a sustainable economic energy efficient reliable manufacturing system with maximum profit by using a control theory approach. The manufacturing system gave the lower amount of defective items, as the management took the reliable manufacturing system by controlling a system failure rate under the efficient use of optimum energy and carbon footprint. The demand of products for the manufacturing system was dependent on the selling-price of items. The profit is maximized globally and analytically under the efficient utilization of energy and carbon footprint at the optimum level of the failure rate, which is an indicator of system reliability. It was found that if the business production cycle was reduced, the profit was reduced but the failure rate increased, which was an indicator of a non-reliable production system through the energy consumption being obviously reduced compared to the increasing consumption due to an increased failure rate. Another major corelation was found between the inflation rate and system failure rate; the increased inflation rate gave a less reliable production system. From the sensitivity analysis, it was found that the selling-price and material cost are the most sensitive parameters compared to others. Therefore, the industry managers have to be more careful to choose perfect material and optimum selling-price to obtain a sustainable manufacturing system such that the optimum energy and carbon footprint are needed. The model considered that the time horizon was finite and that there is no shortage within the system even through defective production was there. This is the limitation of this model. Therefore, an immediate extension of this model can be considered by assuming the shortage within the model when the energy consumption and carbon footprint may take an important role. Another extension of this model can be considered as production disruption, inclusion of corrective and preventive maintenance for a multi-item production system with effectiveness of renewable and non-renewable energy. If the real data is available from an industry, then through data mining techniques, this model can be extended again for further study regarding the effect of energy in a sustainable production system. As this is a multi-item production model, the space and budget constraints can immediately be incorporated within the model, and the Kharush-Kuhn-Tucker method can be applied for optimization, which is another immediate extension of the problem.

Author Contributions: Data curation, software, formal analysis, investigation, writing — original draft preparation, M.S.; data curation-literature review, S.K.; analysis, methodology— writing, J.J.; revision, review—editing, B.G.; conceptualization, methodology, validation, visualization, funding acquisition, supervision, project administration, writing-review and editing, B.S.

Funding: The research was funded by the research fund of Hanyang University (HY-2019-N) (Project number: 201900000000419).

Acknowledgments: This work was supported by the research fund of Hanyang University (HY-2019-N) (Project number: 201900000000419).

Conflicts of Interest: The authors declare no conflict of interest. 


\section{Appendix A}

$$
\begin{aligned}
\Omega_{3}(\eta)= & Y_{1}+\left\{\frac{m_{1} m_{2}\left(\eta+\frac{\tau}{2 \alpha}\right)}{(\eta-\tau)^{2}}+\frac{m_{2} X_{4}}{\tau(\eta-\tau)}\right\}\left(e^{(\eta-\tau) T}-1\right)-\frac{m_{2} \tau N_{i}}{n}\left(e^{\eta T}-1\right) \\
& -\left\{\frac{m_{2} a\left(\tau+\frac{b}{2 \alpha}\right)}{(b-\tau)(b-\tau+\eta)}+\frac{m_{2} a b}{b-\tau+\eta}\right\}\left(e^{(b-\tau+\eta) T}-1\right) \\
& -\frac{m_{2}^{2}\left(\eta+\frac{\tau}{2 \alpha}\right)}{(\eta-\tau)(2 \eta-\tau)}\left(e^{(2 \eta-\tau) T}-1\right)-\alpha\left[Y_{2}+\frac{m_{2}^{2}\left(\eta+\frac{\tau}{2 \alpha}\right)^{2}}{(\eta-\tau)^{2}(2 \eta-\tau)}\left(e^{(2 \eta-\tau) T}-1\right)\right. \\
& \left.+\frac{2 m_{2} m_{3}\left(\eta+\frac{\tau}{2 \alpha}\right)}{(\eta-\tau)}(b+\eta-\tau)\left(e^{(b+\eta-\tau) T}-1\right)-\frac{2 m_{2} x_{4}\left(\eta+\frac{\tau}{2 \alpha}\right)}{\tau(\eta-\tau)^{2}}\left(e^{(\eta-\tau) T}-1\right)\right] \\
& +Y_{3}-\frac{m_{7} m_{2}\left(\eta+\frac{\tau}{2 \alpha}\right)}{\eta(\eta-\tau)}\left(e^{(\eta-\tau) T}-1\right)-\frac{m_{8} m_{2}\left(\eta+\frac{\tau}{2 \alpha}\right)}{\eta(\eta-\tau)}\left\{\frac{T e^{(\eta-\tau) T}}{\eta-\tau}\right. \\
& \left.-\frac{1}{(\eta-\tau)^{2}}\left(e^{(\eta-\tau) T}-1\right)\right\}+\frac{\left.\left.A^{\prime}\right)+B e^{\frac{k(\eta \max -\eta)}{\eta-\eta} \min }\right]}{\tau}\left(e^{-\tau T}-1\right)
\end{aligned}
$$

where

$$
\begin{aligned}
X_{1} & =\left[\left(p_{i}-C_{0_{i}}-C_{0_{i}}^{\prime}-C_{d_{i}} e^{\eta t} \xi-C_{d_{i}}^{\prime} e^{\eta t} \xi\right)-2 \alpha\left(\dot{Q}_{i}+a e^{b t}+\frac{p_{\max }-p_{i}}{p_{i}-p_{\min }}\right)\right] \\
X_{2} & =\left[C_{h_{1 i}}+C_{h_{1 i}}^{\prime}+C_{h_{2 i}}+C_{h_{2 i}}^{\prime}+C_{i}+C_{i}^{\prime}\right] \\
X_{3} & =a e^{b t}\left(\tau+\frac{b}{2 \alpha}\right)+\left(C_{d_{i}}-C_{d_{i}}^{\prime}\right) \xi e^{\eta t}\left(\eta+\frac{\tau}{2 \alpha}\right) \\
X_{4} & =-\frac{1}{2 \alpha}\left[C_{h_{1 i}}+C_{h_{1 i}}^{\prime}+C_{h_{2 i}}+C_{h_{2 i}}^{\prime}+C_{i}+C_{i}^{\prime}-2 \alpha \tau\left(\frac{p_{\max }-p_{i}}{p_{i}-p_{\min }}\right)+\tau\left(p_{i}-C_{0_{i}}-C_{0_{i}}^{\prime}\right)\right] \\
X_{5} & =\left(p_{i}-\left(C_{0_{i}}+C_{0_{i}}^{\prime}\right)-\left(C_{d_{i}}+C_{d_{i}}^{\prime}\right) \xi\right) \\
X_{6} & =\left(C_{h_{1}}+C_{h_{1}}^{\prime}+C_{h_{2_{i}}} t+C_{h_{2_{i}}}^{\prime} t+C_{i}+C_{i}^{\prime}\right) \\
X_{7} & =\left(A+A^{\prime}\right)+B e^{\frac{k(\eta \max }{\left(\eta-\eta \eta_{\min }\right)}} \\
X_{8} & =\left[N_{i} e^{t}+2 X_{4}+a e^{b t}\left(\frac{b}{2 \alpha}+\tau\right)(b+1)+a e^{b t}+\frac{p_{\max }-p_{i}}{p_{i}-p_{\min }}\right] X_{5} \\
& -\alpha\left(N_{i} e^{t}+2 X_{4}+a e^{b t}\left(\frac{b}{2 \alpha}+\tau\right)(b+1)+a e^{b t}+\frac{p_{\max }-p_{i}}{p_{i}-p_{\min }}\right)^{2} \\
& -\left[M_{i}+N_{i} e^{t}+2 X_{4} t+a e^{b t}\left(\frac{b}{2 \alpha}+\tau\right)(b+1)\right] X_{6},
\end{aligned}
$$




$$
\begin{aligned}
& m_{1}=\left(p_{i}-\left(C_{o_{i}}+C_{o_{i}}^{\prime}\right)\right), \\
& m_{2}=\left(C_{d_{i}}+C_{d_{i}}^{\prime}\right), \\
& m_{3}=\frac{a\left(\tau+\frac{b}{2 \alpha}\right)}{(b-\tau)}, \\
& m_{4}=\frac{p_{\max }-p_{i}}{p_{i}-p_{\min }}, \\
& m_{5}=\frac{a\left(\tau+\frac{b}{2 \alpha}\right) e^{b t}}{b(b-\tau)}, \\
& m_{7}=C_{h_{1 i}}+C_{h_{1 i}}^{\prime}+C_{i}+C_{i}^{\prime}, \\
& m_{8}=C_{h_{2 i}}+C_{h_{2 i}}^{\prime}
\end{aligned}
$$

and

$$
\begin{aligned}
Y_{4}= & Y_{1}-\alpha Y_{2}+Y_{3}+\frac{\left(A+A^{\prime}\right)}{\tau}\left(e^{\tau T}-1\right), \\
Y_{1}= & m_{1} \tau N_{i} T+m_{1} \frac{a\left(T+\frac{b}{2 \alpha}\right)}{(b-\tau)^{2}}\left(e^{(b-\tau) T}-1\right)+\frac{m_{1} x_{4}}{\tau^{2}}\left(e^{-\tau T}-1\right) \\
& +\frac{m_{1} a b}{(b-\tau)}\left(e^{(b-\tau) T}-1\right)-\frac{m_{1} m_{4}}{\tau}\left(e^{-\tau T}-1\right)+\frac{m_{2} m_{4}}{\tau}\left(e^{-\tau T}-1\right) \\
Y_{2}= & \tau N_{i}^{2}\left(e^{\tau T-1}\right)+\frac{\left(m_{3}^{2}+a^{2} b^{2}\right)}{(2 b-\tau)}\left(e^{(2 b-\tau) T}-1\right)-\frac{\left(x_{4}^{2}+\tau^{2} m_{4}^{2}\right)}{\tau^{3}}\left(e^{-\tau T}-1\right. \\
& \left.+\frac{2\left(\tau^{2} N_{i} m_{3}-x_{4} a b+\tau m_{4} a b\right)}{\tau(b-\tau)}\right)\left(e^{(b-\tau) T}\right)+2 m_{4} \tau N_{i} T \\
Y_{3}= & m_{7}\left[\frac{M_{i}}{\tau}\left(e^{-\tau T}-1\right)-\frac{x_{4}}{\tau}\left\{\frac{T e^{-\tau T}}{\tau}+\frac{1}{\tau^{2}}\left(e^{-\tau T}-1\right)\right\}-N_{i} T-\frac{m_{5}}{b-\tau}\left(e^{(b-\tau) T}-1\right)\right] \\
& +m_{8}\left[M_{i}\left\{\frac{T}{\tau}\left(e^{-\tau T}-1\right)\right\}+\frac{N_{i} T^{2}}{2}+m_{5}\left\{\frac{T}{(b-\tau)} e^{(b-\tau) T}-\frac{1}{(b-\tau)^{2}}\left(e^{(b-\tau) T}-1\right)\right\}\right. \\
& \left.+\frac{x_{4}}{\tau}\left\{\frac{T^{2}}{\tau} e^{-\tau T}+\frac{2}{T}\left(\frac{T e^{-\tau t}}{\tau}+\frac{1}{T^{2}}\left(e^{-\tau T}-1\right)\right)\right\}\right]
\end{aligned}
$$




\section{Appendix B}

$$
\begin{aligned}
& F_{1}(\eta)=\frac{T m_{1} m_{2}\left(\eta+\frac{\tau}{2 \alpha}\right)}{(\eta-\tau)^{2}} e^{(\eta-\tau) T}+\frac{T m_{2} x_{4} e^{(\eta-\tau) T}}{\tau(\eta-\tau)}-\frac{m_{2} \tau N_{i}}{\eta^{2}}\left(e^{\eta T}-1\right) \\
& +\frac{m_{1} m_{2}}{(\eta-\tau)^{2}}\left(e^{(\eta-\tau) T}-1\right)-\frac{2 m_{1} m_{2}\left(\eta+\frac{\tau}{2 \alpha}\right)}{(\eta-\tau)^{3}}\left(e^{(\eta-\tau) T}-1\right) \\
& -\frac{m_{2} x_{4}}{\tau(\eta-\tau)^{2}}\left(e^{(\eta-\tau) T}-1\right)-\frac{T N_{i} \tau m_{2}}{\eta} e^{\eta T} \\
& +\frac{m_{2} a\left(\tau+\frac{b}{2 \alpha}\right)}{(b-\tau)(b-\tau-\eta)^{2}}\left(e^{-(b-\tau-\eta) T}-1\right) \\
& F_{2}(\eta)=\frac{m_{2} a b\left(e^{(b-\tau+\eta)}-1\right)}{(b-\tau+\eta)^{2}}-\frac{a T m_{2}\left(\tau+\frac{b}{2 \alpha}\right)}{(b-\tau)(b-\tau+\eta)} e^{(b-\tau+\eta) T}-\frac{m_{2} a b T e^{(b-\tau+\eta) T}}{(b-\tau+\eta)} \\
& -\frac{2 T m_{2}^{2}\left(\eta+\frac{\tau}{2 \alpha}\right)}{(\eta-\tau)(2 \eta-\tau)} e^{(2 \eta-\tau) T}-\frac{m_{2}^{2}}{(\eta-\tau)^{2}(2 \eta-\tau)^{2}}\left(e^{(2 \eta-\tau) T}-1\right) \\
& +\frac{m_{2}^{2}\left(\eta+\frac{\tau}{2 \alpha}\right)(4 \eta-3 \tau)}{(\eta-\tau)^{2}(2 \eta-\tau)^{2}}\left(e^{(2 \eta-\tau) T}-1\right)-\frac{2 \alpha m_{2}^{2}\left(\eta_{2}+\frac{\tau}{2 \alpha}\right)\left(e^{(2 \eta-\tau)}-1\right)}{(\eta-\tau)^{2}(2 \eta-\tau)} \\
& F_{3}(\eta)=\frac{2 \alpha m_{2}^{2}\left(\eta+\frac{\tau}{1 \alpha}\right)^{2}(3 \eta-2 \tau)}{(\eta-\tau)^{3}(2 \eta-\tau)^{2}}\left(e^{(2 \eta-\tau) T}-1\right)-\frac{2 \alpha m_{2}^{2} T\left(\eta+\frac{\tau}{2 \alpha}\right)^{2}}{(\eta-\tau)^{2}(2 \eta-\tau)}\left(e^{(2 \eta-\tau)}-1\right) \\
& -\frac{2 \alpha m_{2} m_{3}}{(\eta-\tau)^{2}(b+\eta-\tau)}\left(e^{(b+\eta-\tau) T}-1\right)+\frac{2 \alpha m_{2} m_{3}\left(\eta+\frac{\tau}{2 \alpha}\right)(b+2 \eta-2 \tau)}{(\eta-\tau)^{2}(b+\eta-\tau)^{2}} \\
& -\frac{2 \alpha T m_{2} m_{3} e^{(b+\eta-\tau) T}}{(\eta-\tau)(b+\eta-\tau)}+\frac{2 \alpha m_{2} x_{4}}{\tau}\left(e^{(\eta-\tau) T}-1\right)-\frac{2 \alpha m_{2} x_{4}\left(\eta+\frac{\tau}{2 \alpha}\right)}{\tau(\eta-\tau)^{2}}\left(e^{(\eta-\tau)}-1\right) \\
& F_{4}(\eta)=\frac{2 \alpha m_{2} x_{4} T\left(\eta+\frac{\tau}{2 \alpha}\right)}{\tau(\eta-\tau)^{2}} e^{(\eta-\tau) T}-\frac{m_{2} m_{1}}{\eta(\eta-\tau)^{2}}\left(e^{(\eta-\tau) T}-1\right) \\
& +\frac{m_{2} m_{7}\left(\eta+\frac{\tau}{2 \alpha}\right)(2 \eta-\tau)}{\eta^{2}(\eta-\tau)^{2}}\left(e^{(\eta-\tau) T}-1\right)-\frac{m_{2} m_{7} T\left(\eta+\frac{\tau}{2 \alpha}\right)}{\eta(\eta-\tau)} e^{(\eta-\tau) T} \\
& F_{5}(\eta)=-\left(\frac{m_{2} m_{8}}{\eta(\eta-\tau)}-\frac{m_{2} m_{8}\left(\eta+\frac{\tau}{2 \alpha}\right)(2 \eta-\tau)}{\eta^{2}(\eta-\tau)^{2}}\right)\left\{\frac{T e^{(\eta-\tau) T}}{(\eta-\tau)}-\frac{1}{(\eta-\tau)^{2}}\left(e^{(\eta-\tau) T}-1\right)\right\} \\
& -\frac{m_{2} m_{8}\left(\eta+\frac{\tau}{2 \alpha}\right)}{(\eta-\tau)}\left\{\frac{T^{2} e^{(\eta-\tau) T}}{(\eta-\tau)}-\frac{T e^{(\eta-\tau) T}}{(\eta-\tau)^{2}}-\frac{T e^{(\eta-\tau) T}}{(\eta-\tau)^{4}}+\frac{2\left(e^{(\eta-\tau) T}\right)-1}{(\eta-\tau)^{3}}\right. \\
& \left.-\frac{(B+\dot{B})}{\tau}\left(e^{-\tau T}-1\right) \frac{K\left(\eta_{\max }-\eta_{\min }\right)}{\left(\eta-\eta_{\min }\right)^{2}} \frac{K\left(\eta_{\max }-\eta\right)}{\left(\eta-\eta_{\min }\right)}\right\}
\end{aligned}
$$

\section{References}

1. Cárdenas-Barrón, L.E.; Sarkar, B.; Treviño-Garza, G. An improved solution to the replenishment policy for the EMQ model with rework and multiple shipments. Appl. Math. Mod. 2013, 37, 5549-5554. [CrossRef]

2. Sana, S.S. A production inventory model in an imperfect production process. Eur. J. Oper. Res. 2010, 200, 451-464. [CrossRef]

3. Mettas, A. Reliability allocation and optimization for complex systems. In Annual Reliability and Maintainability Symposium. 2000 Proceedings. International Symposium on Product Quality and Integrity; IEEE: Piscataway, NJ, USA, 2000; pp. 216-221. [CrossRef]

4. Cao, Q.; Schniederjans, M.J. A revised EMQ/JIT production-run model: An examination of inventory and production costs. Int. J. Prod. Econ. 2004, 87, 83-95. [CrossRef]

5. Wang, C.H. The impact of a free-repair warranty policy on EMQ model for imperfect production systems. Comput. Oper. Res. 2004, 31, 2021-2035. [CrossRef]

6. Giri, B.; Dohi, T. Computational aspects of an extended EMQ model with variable production rate. Comput. Oper. Res. 2005, 32, 3143-3161. [CrossRef] 
7. Sarkar, B.; Sana, S.S.; Chaudhuri, K. Optimal reliability, production lotsize and safety stock: An economic manufacturing quantity model. Int. J. Manag. Sci. Eng. Manag. 2010, 5, 192-202. [CrossRef]

8. Sarkar, B.; Sana, S.S.; Chaudhuri, K. Optimal reliability, production lot size and safety stock in an imperfect production system. Int. J. Math. Oper. Res. 2010, 2, 467-490. [CrossRef]

9. Sarkar, B.; Sana, S.S.; Chaudhuri, K. A stock-dependent inventory model in an imperfect production process. Int. J. Proc. Manag. 2010, 3, 361-378. [CrossRef]

10. Chiu, Y.S.P.; Liu, S.C.; Chiu, C.L.; Chang, H.H. Mathematical modeling for determining the replenishment policy for EMQ model with rework and multiple shipments. Math. Comput. Mod. 2011, 54, 2165-2174. [CrossRef]

11. Sarkar, B.; Sana, S.S.; Chaudhuri, K. An imperfect production process for time varying demand with inflation and time value of money-An EMQ model. Exp. Syst. Appl. 2011, 38, 13543-13548. [CrossRef]

12. Sarkar, B. An inventory model with reliability in an imperfect production process. Appl. Math. Comput. 2012, 218, 4881-4891. [CrossRef]

13. Sarkar, B.; Mandal, P.; Sarkar, S. An EMQ model with price and time dependent demand under the effect of reliability and inflation. Appl. Math. Comput. 2014, 231, 414-421. [CrossRef]

14. Sarkar, B.; Saren, S. Product inspection policy for an imperfect production system with inspection errors and warranty cost. Eur. J. Oper. Res. 2016, 248, 263-271. [CrossRef]

15. Omair, M.; Sarkar, B.; Cárdenas-Barrón, L.E. Minimum Quantity Lubrication and Carbon Footprint: A Step towards Sustainability. Sustainablity 2017, 9, 714. [CrossRef]

16. Jaber, M.Y.; Bonney, M.; Jawad, H. Comparison between economic order/manufacture quantity and just-in-time models from a thermodynamics point of view. Comput. Ind. Eng. 2017, 112, 503-510. [CrossRef]

17. Ahmed, W.; Sarkar, B. Impact of carbon emissions in a sustainable supply chain design for a second generation biofuel. J. Clean. Prod. 2018, 186, 807-820. [CrossRef]

18. Tiwari, S.; Daryanto, Y.; Wee, H.M. Sustainable inventory management with deteriorating and imperfect quality items considering carbon emission. J. Clean. Prod. 2018, 176, 154-169. [CrossRef]

19. Sarkar, M.; Sarkar, B. Optimization of safety stock under controllable production rate and energy consumption in a smart production management. Energies 2019, 12, 2059. [CrossRef]

20. Kluczek, A. An energy-led sustainability assessment of production systems-An approach for improving energy efficiency performance. Int. J. Prod. Econ. 2019, 216, 190-203. [CrossRef]

21. Harris, T.M.; Devkota, J.P.; Khanna, V.; Eranki, P.L.; Landis, A.E. Logistic growth curve modeling of US energy production and consumption. Renew. Sustain. Energy Rev. 2018, 96, 46-57. [CrossRef]

22. Dehning, P.; Blume, S.; Dér, A.; Flick, D.; Herrmenn, C.; Thiede, S. Load profile analysis for reducing energy demands of production systems in non-production times. Appl. Energy 2019, 237, 117-130. [CrossRef]

23. Khalil, M.; Berawi, M.A.; Heryanto, R.; Rizalie, A. Waste to energy technology: The potential of sustainable biogas production from animal waste in Indonesia. Renew. Sustain. Energy Rev. 2019, 105, 323-331. [CrossRef]

24. Nižetić, S.; Djilali, N.; Papadopoulos, A.; Rodrigues, J.J.P.C. Smart technologies for promotion of energy efficiency, utilization of sustainable resources and waste management. J. Clean. Prod. 2019. [CrossRef]

25. Biel, K.; Glock, C.H. On the use of waste heat in a two-stage production system with controllable production rates. Int. J. Prod. Econ. 2016, 181, 174-190. [CrossRef]

26. Sarkar, B. An EOQ model with delay in payments and stock dependent demand in the presence of imperfect production. Appl. Math. Comput. 2012, 218, 8295-8308. [CrossRef]

27. Sarkar, B.; Saren, S.; Sinha, D.; Hur, S. Effect of unequal lot sizes, variable setup cost, and carbon emission cost in a supply chain model. Math. Probl. Eng. 2015, 2015, 1-13. [CrossRef]

28. San-Jośe, L.A.; Sicilia, J.; Cárdenas-Barrón, L.E.; Gutiérrez, J.M. Optimal price and quantity under power demand pattern and non-linear holding cost. Comput. Ind. Eng. 2019, 129, 426-434. [CrossRef]

29. Sarkar, B. Supply chain coordination with variable backorder, inspections, and discount policy for fixed lifetime products. Math. Probl. Eng. 2016, 2016, 1-14. [CrossRef]

30. Shin, D.; Guchhait, R.; Sarkar, B.; Mittal, M. Controllable lead time, service level constraint, and transportation discounts in a continuous review inventory model. RAIRO-Oper. Res. 2016, 50, 921-934. [CrossRef]

31. Cárdenas-Barrón, L.E.; González-Velarde, J.L.; Treviño-Garza, G. Heuristic algorithm based on reduce and optimize approach for a selective and periodic inventory routing problem in a waste vegetable oil collection environment. Int. J. Prod. Econ. 2019, 211, 44-59. [CrossRef] 
32. Manente, G.; Lazzaretto, A.; Molinari, I.; Bronzini, F. Optimization of the hydraulic performance and integration of a heat storage in the geothermal and waste-to-energy district heating system of Ferrara. J. Clean. Prod. 2019, 230, 869-887. [CrossRef]

33. Govindan, K.; Jha, P.C.; Agarwal, V.; Darbari, J.D. Environmental management partner selection for reverse supply chain collaboration: A sustainable approach. J. Environ. Manag. 2019, 236, 784-797. [CrossRef] [PubMed]

34. Sarkar, B.; Majumder, A.; Sarkar, M.; Dey, B.K.; Roy, G. Two-echelon supply chain model with manufacturing quality improvement and setup cost reduction. J. Ind. Manag. Opt. 2017, 13, 1085-1104. [CrossRef]

35. Sarkar, B.; Ullah, M.; Kim, N. Environmental and economic assessment of closed-loop supply chain with remanufacturing and returnable transport items. Comput. Ind. Eng. 2017, 111, 148-163. [CrossRef]

36. Govindan, K.; Jiménez-Parra, B.; Rubio, S.; Vicente-Molina, M.A. Marketing issues for remanufactured products. J. Clean. Prod. 2019, 227, 890-899. [CrossRef]

37. Govindan, K.; Agarwal, V.; Darbari, J.D.; Jha, P.C. An integrated decision making model for the selection of sustainable forward and reverse logistic providers. Ann. Oper. Res. 2019, 273, 607-650. [CrossRef]

(c) 2019 by the authors. Licensee MDPI, Basel, Switzerland. This article is an open access article distributed under the terms and conditions of the Creative Commons Attribution (CC BY) license (http://creativecommons.org/licenses/by/4.0/). 